\title{
Arrhythmias in pulmonary arterial hypertension
}

\author{
Ian Peter Temple
}

\begin{abstract}
Pulmonary arterial hypertension is a condition associated with raised right heart pressures and subsequent remodelling of the right atrium and ventricle with relative preservation of left heart function. There is a high incidence of arrhythmias including atrial fibrillation, atrial flutter and atrioventricular nodal re-entrant tachycardia. Despite recent advances in medical therapy for pulmonary arterial hypertension arrhythmias continue to have a high morbidity and mortality. Treatment includes medical therapy, cardioversion and catheter ablation.

Keywords: Pulmonary arterial hypertension, Arrhythmia, Atrial fibrillation, Atrial flutter, Atrioventricular nodal re-entrant tachycardia
\end{abstract}

\section{Background}

Pulmonary hypertension is a haemodynamic state defined as a mean pulmonary artery pressure greater than $25 \mathrm{mmHg}$ whilst the patient is at rest. It is not a single entity and has multiple causes. The causes of pulmonary hypertension are sub-classified into five diagnostic categories; pulmonary arterial hypertension (PAH), pulmonary hypertension due to left heart disease, pulmonary hypertension due to lung disease or hypoxia, chronic thromboembolic pulmonary hypertension and a final multifactorial group. These clinical groups are organised on the basis of shared pathological mechanisms and response to treatment [1].

PAH may be due to many causes but the common factor is that the rise in pulmonary pressures is mediated by vascular remodelling within the vessel wall of the pulmonary artery [2]. In patients with PAH the right ventricle needs to produce much higher pressures than in the general population in order to generate a pressure gradient across the pulmonary circulation and maintain adequate flow. This results in remodelling of the right ventricle with relative preservation of left ventricular function. Initially there is compensatory right ventricular hypertrophy with both the right ventricular wall thickness and right ventricular mass significantly increased [3, 4]. In patients with more advanced PAH

Correspondence: ian.temple3@nhs.net

University Hospital South Manchester, Southmoor Road, Manchester M23 9LT, UK

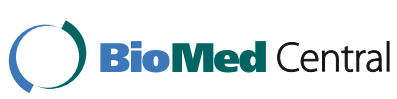

both systolic and diastolic right ventricular volumes are increased with a decrease in right ventricular ejection fraction [3-6]. In severe PAH both systolic and diastolic right ventricular function is reduced and stroke volumes are significantly lower resulting in right heart failure [3-6].

\section{Review}

Cohort studies following groups of patients with either idiopathic PAH, all forms of PAH or a combined group of PAH and chronic thromboembolic pulmonary hypertension patients have shown a prevalence of arrhythmias of around $15-20 \%$ in world health organisation class III and IV PAH patients [7-10]. Between these different patient populations there are consistently high rates of all supraventricular arrhythmias including atrial fibrillation $(\mathrm{AF})$, atrial flutter and atrioventricular re-entrant tachycardia (AVNRT). Interestingly these studies have shown a similar distribution of the types of arrhythmias seen with approximately $40 \%$ of patients having atrial fibrillation, $40 \%$ flutter, $10 \%$ atrial tachycardia and 10\% atrioventricular nodal re-entrant tachycardia [7-9]. In a study of patients with congenital heart disease and confirmed pulmonary hypertension due to the Eisenmenger reaction the majority were in sinus rhythm at the start of the study with only $2 \%$ of patients in atrial fibrillation. During the 5 year follow up period arrhythmias were seen in $13 \%$ of patients, however, the nature of the arrhythmia was not specified [11]. In a separate study 
9\% of patients with congenital heart disease and confirmed pulmonary hypertension due to the Eisenmenger reaction developed atrial fibrillation or flutter during follow up, it is interesting to note that the median follow up period during this study was 31 years [12].

The evidence for ventricular arrhythmias in PAH is more limited although studies have shown a prolonged QT interval and an increased frequency of ventricular ectopics.[13] In a cohort of patients with the congenital heart disease and the Eisenmenger reaction there was evidence of more sustained ventricular arrhythmias with $5 \%$ of patients demonstrating ventricular tachycardia although the demonstration of ventricular tachycardia was not associated with sudden cardiac death [12]. In a retrospective analysis of 3110 patients with PAH over 3 years in a multicentre study 513 patients died, and of these $17 \%$ were due to sudden and unexpected causes. Approximately one quarter of the patients who died underwent cardio-pulmonary resuscitation and of these patients ventricular fibrillation was seen in $8 \%$ of cases [14].

There is also some evidence of sinus and atrioventricular node dysfunction in the PAH population. At the initial screening of a cohort of 51 untreated patients with PAH two patients had sinus bradycardia, and a further 6 patients had $1^{\text {st }}$ degree atrioventricular heart block, with one patient requiring a dual chamber pacemaker for higher degree heart block. The mean PR duration in this cohort was $180 \pm 50 \mathrm{~ms}$ [15].

Studies looking at arrhythmias in PAH have defined the incidence and prevalence of arrhythmias in a population of patients PAH but have not made a comparison with a matched cohort of apparently healthy individuals $[8,16]$. The incidence and prevalence of arrhythmias quoted from studies of the general population are not age and sex matched with studies of patients with PAH and may include people with other cardiac comorbidities $[17,18]$. This makes comparison of the rates of arrhythmias in PAH with apparently healthy individuals difficult and liable to underestimate the increase in arrhythmias due to the effect of PAH, however, some inferences can be made.

The approximately $20 \%$ prevalence of arrhythmias in the studies described above is in marked contrast to those within the general population which suggest a much lower prevalence of all forms of supraventricular arrhythmias at only $0.23 \%$ [17].

Predictors for the development of an arrhythmia in $\mathrm{PAH}$ include a poor functional status, increased right atrial and right ventricular size, increased right atrial pressure, raised pulmonary vascular resistance, increased BNP, increased bilirubin and a lower cardiac output $[9,10]$.

Human imaging studies have demonstrated a high incidence of fibrosis within the right ventricle of patients with PAH [19]. In those patients with demonstrable fibrosis in the right ventricle there is a poor outcome although there is no evidence to link this directly to arrhythmias [19]. Animal studies have also shown remodelling in the right ventricle with increased fibrosis, myocardial fibre disarray and alterations in the ion channels, connexins and calcium handling proteins critical for impulse generation and propagation [20].

Taken together both the human and animal studies point to the fact that as PAH develops there is progressive remodelling, particularly in the right atrium that promotes the formation of arrhythmias.

A comparison of the relative distribution of the different types of arrhythmias seen in the PAH population with the general population shows that the ratio of atrial flutter:AF cases is approximately 1:5 in the general population whereas in the $\mathrm{PAH}$ populations it is close to $1: 1[7-10,18]$. It is perhaps not surprising that atrial flutter is disproportionately more prevalent in patients with PAH. The generation of typical atrial flutter depends on an anatomical substrate which is located within the right atrium. Within this circuit both an increase in the length of the circuit and a slowing of conduction time will promote the generation and maintenance of typical atrial flutter. As described above the both right atrial pressure and right atrial dimensions are predictors of developing and arrhythmia [9]. In addition to structural remodelling electrophysiological assessment of a population of patients with PAH but no evidence of arrhythmias has shown slowing of conduction in the right atrium. These changes may provide the substrate necessary for the maintenance of atrial flutter [21].

It is also notable that there is a high proportion of AVNRT with no cases of accessory pathway mediated tachycardia (i.e. atrioventricular re-entrant tachycardia) in PAH patients in two of the cohort studies described above $[7,8]$. This suggests that AVNRT is due to remodelling in response to PAH rather than due congenital abnormalities in conduction. Although AVNRT results in a tachycardia it is caused by a re-entrant circuit located within this AV node. Maintenance of the circuit is dependent on the balance between the speed of conduction and the refractory periods of the fast and slow pathways within the AV node [22]. Remodelling within the AV node leading to either an increase or decrease in the conduction velocity or refractory period will alter the balance between these factors and could therefore promote the generation of AVNRT. There are no studies designed to elucidate which of these factors are affected in PAH.

As described above pulmonary hypertension can be caused by raised left heart pressures with 'back-pressure' transmitted to the pulmonary artery and a subsequently raised right heart pressures. Raised post capillary 
pressures in the lung imply that the increased pressure within the pulmonary artery is a result of increased pressure within the left atrium. This may be as a result of systolic or diastolic left ventricular dysfunction or valvular heart disease [1]. The development of pulmonary hypertension secondary to any form of left heart disease is associated with poor outcomes regardless of the aetiology of the left sided heart disease.

Left atrial size has been shown to be correlated with left atrial pressure across a range of conditions affecting the left heart including ischaemic and non-ischaemic cardiomyopathy, mitral valve disease and aortic valve disease [23]. An increase in left atrial size predicts poor cardiovascular outcomes including the development of atrial fibrillation [23]. In addition to this the presence of atrial fibrillation predicts the presence of pulmonary hypertension and reduction in right ventricular function in patients with a reduced left ventricular ejection fraction [24]. These findings suggests a direct role for raised left atrial pressures and size in the generation of atrial arrhythmias but also demonstrates that raised right heart pressures coexist with these changes in the left atrium. There is no direct evidence to elucidate the role that raised right heart pressures may play in the generation of arrhythmias in patients in whom pulmonary hypertension is a result of left sided heart disease. The increase rates of atrial arrhythmias could simply be as a result of more extensive remodelling within the left atrium but may also point to the development of raised pulmonary pressures and subsequent remodelling within the right atrium.

Patients with significantly impaired left ventricular function and heart failure due to both idiopathic dilated cardiomyopathy and ischaemic cardiomyopathies are at an increased risk of sudden cardiac death secondary to ventricular arrhythmias. There are multiple mechanisms that contribute to the generation of these arrhythmias including scar formation, fibrosis, ion channel remodelling, alteration of calcium handling and alterations of cell:cell coupling [25]. These mechanisms are well described within the left ventricle however there is less information with regards to the secondary effects on the right ventricle due to the development of pulmonary hypertension [25]. In a study of explanted hearts from patients undergoing cardiac transplantation for left heart failure there was significant alterations in the action potential, ion channel expression, calcium handling proteins expression and cell:cell coupling within the right ventricle [26]. This raises the possibility that the development of pulmonary hypertension secondary to left heart disease could cause remodelling within the right ventricle with a subsequent increase in the risk of ventricular arrhythmias.

When patients with PAH develop an arrhythmia it is often poorly tolerated and leads to a deterioration in functional class, right ventricular failure and hospital admission. This may be due to a combination of factors including the loss of atrial contraction, the loss of atrioventricular synchrony and uncontrolled heart rates; all of which can reduce the cardiac output [7-9]. As well as an immediate clinical deterioration the presence of an arrhythmia is an independent predictor of mortality in $\mathrm{PAH}[9,11,12,27]$. There is an intriguing paradox in the observation that patients with pulmonary hypertension due to congenital heart disease and PAH have a better prognosis than other patients with $\mathrm{PAH}$ and comparable pulmonary artery pressures despite a similar prevalence and severity of arrhythmias. Epidemiological studies suggest that patients with $\mathrm{PAH}$ secondary to congenital heart disease maintain sinus rhythm for a longer period before arrhythmias are seen [12]. Given the multiple possible substrates for arrhythmia in the $\mathrm{PAH}-\mathrm{CHD}$ cohort this is surprising and the protective mechanisms underlying this relative protection from arrhythmias are unclear.

The development of an arrhythmia portends a significantly haemodynamic compromise and increased mortality for all patients with PAH regardless of aetiology $[9,11,12,27]$. If sinus rhythm can be restored and maintained in PAH patients with an arrhythmia the prognosis returns to that expected for those patients that have never had an arrhythmia $[9,10]$. These findings point to the importance of a clinical strategy designed to prevent arrhythmias and restore sinus rhythm in those patients who have developed arrhythmias [7-9].

With regards to the prevention of arrhythmias there is no data to show that using any individual advanced therapy for PAH reduces the risk of arrhythmia but some limited data to suggest that using a combination of advanced therapies may reduce the risk of developing an arrhythmia [9]. There is no data to suggest the use of advanced $\mathrm{PAH}$ therapies to treat arrhythmias once they have developed.

Descriptions of strategies employed to restore sinus rhythm point to the need for aggressive treatments with a combination of medical therapy, cardioversion and invasive ablation procedures. The most common medication used is amiodarone although the use of a variety of other antiarrythmics including beta blockers, verapamil, digoxin, sotalol, dronaderone and flecainide has been described [7-10]. In the general population amiodarone is recognised as the most effective anti-arrhythmic medication across a range of clinical scenarios, it also benefits from having only a minimal negatively inotropic effect. Despite this the use of amiodarone is often limited by the high frequency of side effects and adverse reactions including thyroid, lung, liver and skin problems [28]. There are no randomised controlled trials to guide the choice of medications used within the $\mathrm{PAH}$ population 
but given the clinical significance of arrhythmias described above it seems very reasonable that amiodarone continues to be the mainstay of arrhythmic drug therapy until newer more effective therapies can be developed. If anti-arrhythmic therapy alone is not able to restore sinus rhythm it can be combined with electrical DC cardioversion. This is often successful in restoring sinus rhythm acutely but with high rates of recurrence of arrhythmias [7-9].

As described above atrial flutter is disproportionately more common in patients with PAH and electrophysiological studies have demonstrated that this atrial flutter is frequently 'typical, i.e. related to a well described reentrant circuit in the right atrium. This circuit is dependent on conduction across an isthmus of tissue between the tricuspid valve and inferior vena cava which can be safely and easily ablated with radiofrequecy catheter ablation [29]. This treatment is highly effective in the general population and studies in PAH patients have also shown high rates of success with a $100 \%$ acute success rate and approximately $75 \%$ long term success rate $[7,8,21,30]$.

Patients in whom PAH is associated with congenital heart disease represent a particular challenge with respect to arrhythmias. The combination of the underlying structural defects and subsequent operations creates a myriad of different substrates which may be associated with arrhythmia generation, particularly macro-reentrant flutter circuits leaving these patients vulnerable to both typical 'isthmus-dependent' flutter and atypical atrial flutter circuits [31]. There is limited data to point to which types of flutter are more common in the PAH associated with congenital heart disease population. The ECG cannot be used to reliably diagnose 'typical' versus 'atypical' flutter as the ECG in patients with PAH associated with congenital heart disease may show a longer flutter cycle length and abnormal flutter wave morphology despite the rhythm being demonstrated to be 'typical' isthmus-dependent flutter on invasive electrophysiological testing [31]. In the two patients with PAH associated with congenital heart disease described in the literature who have undergone electrophysiological testing [31] the flutter circuits have been demonstrated to by typical 'isthmus-dependent' flutter and in each case was successfully treated with catheter ablation [31].

Similarly to atrial flutter, catheter ablation in AVNRT is focussed on structures located within the right atrium with the aim to disrupt conduction in the slow pathway of the atrioventricular node. The inferior nodal extension, which lies along the tricuspid annulus below the His bundle and in front of the coronary sinus, is thought to be the anatomical correlate of the slow pathway [32]. Disruption of the slow pathway is effective in abolishing AVNRT in the general population and although the data is limited it has been similarly effective when used in PAH patients, albeit that the results are only reported for very small numbers [8].

Ablation based strategies are also increasingly used to achieve and maintain sinus rhythm for AF in the general population. The paradigm for these treatments is to electrically isolate the four pulmonary veins from the left atrium because the pulmonary veins have been shown be the site where rapid ectopic beats often originate which is often the trigger for AF in the general population [33]. Further ablation may also be applied to other regions within the left atrium that can act as the substrate for both the initiation and maintenance of $\mathrm{AF}$ [33]. In contrast to extensive left atrial ablation there is a reduced focus on the right atrium in AF ablation within the general population. Where ablation is performed in the right atrium the creation of a line across the tricuspid isthmus as described above for atrial flutter is the most common ablation performed [33].

There is limited data behind the mechanisms of the increased rates of atrial fibrillation seen in PAH but it seems likely that the slowing of conduction and increased right atrial size described above are important factors; conversely it is hard to envisage a dominant role for pulmonary vein ectopics in the increased rates of $\mathrm{AF}$ seen in the $\mathrm{PAH}$ population given the relative preservation of left heart function [10]. In this context the ablation procedures performed for AF in the general population with their focus on pulmonary vein isolation may not be appropriate in the PAH population and there are no reported studies of any ablation procedures being performed for AF in patients with PAH [10].

Whichever strategy is employed in AF there is a higher failure to restore sinus rhythm than in either atrial flutter or AVNRT [10]. This may be due to the absence of an effective ablation strategy, but it may also be that the development of AF is a marker or more severe remodelling in the right atrium suggesting a more advanced underlying disease process. Regardless of the reasons, failure to restore sinus rhythm in AF is associated with a high mortality [8].

\section{Conclusions}

Overall there are considerable gaps in our knowledge of arrhythmias in PAH in terms of both pathogenesis and optimal management strategy. The mainstay of medical therapy consists of a combination of amiodarone and DC cardioversion. Catheter ablation is effective in restoring and maintaining sinus rhythm in both atrial flutter and AVNRT and may at present be under used. Atrial fibrillation represents a considerable clinical challenge with limited therapeutic options, a high risk of recurrence and an adverse prognosis. 


\section{Abbreviations}

AF: Atrial fibrillation; AVNRT: Atrioventricular re-entrant tachycardia; PAH: Pulmonary arterial hypertension

\section{Acknowledgements}

Not applicable.

\section{Funding}

Grant Support: This work was undertaken with the support of a British Heart Foundation Clinical Research Fellowship, grant number FS/10/69/28495.

\section{Availability of data and materials}

Data sharing not applicable to this article as no datasets were generated or analysed during the current study.

\section{Author's contributions}

IT wrote and edited the article.

\section{Competing interests}

The author declares that he/she has no competing interests.

\section{Consent for publication}

Not applicable.

\section{Ethics approval and consent to participate}

Not applicable.

\section{Publisher's Note}

Springer Nature remains neutral with regard to jurisdictional claims in published maps and institutional affiliations.

\section{Received: 10 June 2015 Accepted: 11 May 2017}

\section{Published online: 27 June 2017}

\section{References}

1. Galie N, Hoeper MM, Humbert M, Torbicki A, Vachiery JL, Barbera JA, et al. Guidelines for the diagnosis and treatment of pulmonary hypertension: the Task Force for the Diagnosis and Treatment of Pulmonary Hypertension of the European Society of Cardiology (ESC) and the European Respiratory Society (ERS), endorsed by the International Society of Heart and Lung Transplantation (ISHLT). Eur Heart J. 2009;30(20):2493-537. doi:ehp297 [pii] 10.1093/eurhearti/ehp297.

2. Schermuly RT, Ghofrani HA, Wilkins MR, Grimminger F. Mechanisms of disease: pulmonary arterial hypertension. Nat Rev Cardiol. 2011;8(8):443-55. doi:10.1038/nrcardio.2011.87nrcardio.2011.87[pii].

3. van Wolferen SA, Marcus JT, Boonstra A, Marques KM, Bronzwaer JG, Spreeuwenberg MD, et al. Prognostic value of right ventricular mass, volume, and function in idiopathic pulmonary arterial hypertension. Eur Heart J. 2007;28(10):1250-7. doi:ehl477 [pii] 10.1093/eurheartj/ehl477.

4. Saba TS, Foster J, Cockburn M, Cowan M, Peacock AJ. Ventricular mass index using magnetic resonance imaging accurately estimates pulmonary artery pressure. Eur Respir J. 2002;20(6):1519-24.

5. McLure LE, Peacock AJ. Cardiac magnetic resonance imaging for the assessment of the heart and pulmonary circulation in pulmonary hypertension. Eur Respir J. 2009:33(6):1454-66. doi:33/6/1454 [pii] 10.1183/ 09031936.00139907

6. Vonk Noordegraaf A, Marcus JT, Roseboom B, Postmus PE, Faes TJ, de Vries PM. The effect of right ventricular hypertrophy on left ventricular ejection fraction in pulmonary emphysema. Chest. 1997:112(3):640-5.

7. Ruiz-Cano MJ, Gonzalez-Mansilla A, Escribano P, Delgado J, Arribas F, Torres J, et al. Clinical implications of supraventricular arrhythmias in patients with severe pulmonary arterial hypertension. Int J Cardiol. 2011;146(1):105-6. doi:10. 1016/j.ijcard.2010.09.065S0167-5273(10)00780-1 [pii].

8. Tongers J, Schwerdtfeger B, Klein G, Kempf T, Schaefer A, Knapp JM, et al. Incidence and clinical relevance of supraventricular tachyarrhythmias in pulmonary hypertension. Am Heart J. 2007;153(1):127-32. doi:S0002 8703(06)00862-3 [pii] 10.1016/j.ahj.2006.09.008

9. Wen $L$, Sun $M L$, An $P$, Jiang $X$, Sun $K$, Zheng $L$, et al. Frequency of Supraventricular Arrhythmias in Patients With Idiopathic Pulmonary Arterial Hypertension. Am J Cardiol. 2014. doi:S0002-9149(14)01601-4 [pii] 10.1016/j. amjcard.2014.07.079.
10. Olsson KM, Nickel NP, Tongers J, Hoeper MM. Atrial flutter and fibrillation in patients with pulmonary hypertension. Int J Cardiol. 2013;167(5):2300-5. doi:10.1016/j.jijcard.2012.06.024S0167-5273(12)00799-1[pii].

11. Diller GP, Dimopoulos K, Broberg CS, Kaya MG, Naghotra US, Uebing A et al. Presentation, survival prospects, and predictors of death in Eisenmenger syndrome: a combined retrospective and case-control study. Eur Heart J. 2006;27(14):1737-42. doi:ehl116 [pii] 10.1093/eurheartj/ehl116.

12. Daliento L, Somerville J, Presbitero P, Menti L, Brach-Prever S, Rizzoli G, et al. Eisenmenger syndrome. Factors relating to deterioration and death. Eur Heart J. 1998;19(12):1845-55. doi:S0195668X98910466 [pii].

13. Yi HT, Hsieh YC, Wu TJ. Huang JL. Lin WW: Liang KW et al. Heart rate variability parameters and ventricular arrhythmia correlate with pulmonary arterial pressure in adult patients with idiopathic pulmonary arterial hypertension. Heart Lung; 2014. doi:S0147-9563(14)00150-2 [pii] 10.1016/j. hrtlng.2014.05.010.

14. Hoeper MM, Galie N, Murali S, Olschewski H, Rubenfire M, Robbins IM, et al. Outcome after cardiopulmonary resuscitation in patients with pulmonary arterial hypertension. Am J Respir Crit Care Med. 2002;165(3):341-4.

15. Bossone E, Paciocco G, larussi D, Agretto A, lacono A, Gillespie BW, et al. The prognostic role of the ECG in primary pulmonary hypertension. Chest. 2002:121(2):513-8.

16. Kanemoto $\mathrm{N}$, Sasamoto $\mathrm{H}$. Arrhythmias in primary pulmonary hypertension. Jpn Heart J. 1979;20(6):765-75.

17. Orejarena LA, Vidaillet Jr H, DeStefano F, Nordstrom DL, Vierkant RA, Smith PN, et al. Paroxysmal supraventricular tachycardia in the general population. J Am Coll Cardiol. 1998;31(1):150-7. doi:S0735-1097(97)00422-1 [pii].

18. Vidaillet H, Granada JF, Chyou P, Maassen K, Ortiz M, Pulido JN, et al. A population-based study of mortality among patients with atrial fibrillation or flutter. Am J Med. 2002;113(5):365-70. doi:S0002934302012536 [pii].

19. Ozawa K, Funabashi N, Kataoka A, Tanabe N, Yanagawa N, Tatsumi K, et al. Myocardial fibrosis in the right ventricle detected on ECG gated 320 slice CT showed a short term poor prognosis in subjects with pulmonary hypertension. Int J Cardiol. 2013;168(1):584-6. doi:10.1016/j.jjcard.2013.01. 251S0167-5273(13)00311-2[pii].

20. Benoist D, Stones R, Drinkhill M, Bernus O, White E. Arrhythmogenic substrate in hearts of rats with monocrotaline-induced pulmonary hypertension and right ventricular hypertrophy. Am J Physiol Heart Circ Physiol. 2011;300(6):H2230-7. doi:10.1152/ajpheart.01226.2010ajpheart.01226. 2010 [pii].

21. Medi C, Kalman JM, Ling LH, Teh AW, Lee G, Spence SJ, et al. Atrial electrical and structural remodeling associated with longstanding pulmonary hypertension and right ventricular hypertrophy in humans. J Cardiovasc Electrophysiol. 2012;23(6):614-20. doi:10.1111/j.1540-8167.2011.02255.x.

22. Markowitz S, Stein K, Mittal S, Lerman B. Dual atrionodal physiology in the human heart. In: Mazgalev T, Tchou, MD, editor. Atrial-AV nodal electrophysiology: a view from the millennium. In: Armonk. New York: Futura Publishing Company; 2000. p. 353-70.

23. Abhayaratna WP, Seward JB, Appleton CP, Douglas PS, Oh JK, Tajik AJ, et al. Left atrial size: physiologic determinants and clinical applications. J Am Coll Cardiol. 2006;47(12):2357-63. doi:S0735-1097(06)00860-6 [pii] 10.1016/j.jacc. 2006.02.048

24. Thenappan T, Gomberg-Maitland M. Epidemiology of pulmonary hypertension and right ventricular failure in left heart failure. Curr Heart Fail Rep. 2014;11(4):428-35. doi:10.1007/s11897-014-0216-6.

25. Coronel R, Wilders $R$, Verkerk AO, Wiegerinck RF, Benoist D, Bernus O. Electrophysiological changes in heart failure and their implications for arrhythmogenesis. Biochim Biophys Acta. 2013;1832(12):2432-41. doi:10. 1016/j.bbadis.2013.04.002S0925-4439(13)00105-1 [pii].

26. Lou Q, Janks DL, Holzem KM, Lang D, Onal B, Ambrosi CM, et al. Right ventricular arrhythmogenesis in failing human heart: the role of conduction and repolarization remodeling. Am J Physiol Heart Circ Physiol. 2012;303(12):H1426-34. doi:10.1152/ajpheart.00457.2012ajpheart. 00457.2012 [pii].

27. Cantor WJ, Harrison DA, Moussadji JS, Connelly MS, Webb GD, Liu P, et al. Determinants of survival and length of survival in adults with Eisenmenger syndrome. Am J Cardiol. 1999:84(6):677-81. doi:S0002914999004154 [pii].

28. van Erven L, Schalij MJ. Amiodarone: an effective antiarrhythmic drug with unusual side effects. Heart. 2010:96(19):1593-600 doi:10.1136/hrt.2008. 15265296/19/1593 [pii].

29. Olgin JE, Kalman JM, Fitzpatrick AP, Lesh MD. Role of right atrial endocardial structures as barriers to conduction during human type I atrial flutter. 
Activation and entrainment mapping guided by intracardiac echocardiography. Circulation. 1995;92(7):1839-48.

30. Showkathali R, Tayebjee MH, Grapsa J, Alzetani M, Nihoyannopoulos P, Howard LS, et al. Right atrial flutter isthmus ablation is feasible and results in acute clinical improvement in patients with persistent atrial flutter and severe pulmonary arterial hypertension. Int J Cardiol. 2011;149(2):279-80. doi:10.1016/j.jijcard.2011.02.059S0167-5273(11)00237-3[pii].

31. Bradfield J, Shapiro S, Finch W, Tung R, Boyle NG, Buch E, et al. Catheter ablation of typical atrial flutter in severe pulmonary hypertension. J Cardiovasc Electrophysiol. 2012;23(11):1185-90.

32. Temple IP, Inada S, Dobrzynski H, Boyett MR. Connexins and the atrioventricular node. Heart Rhythm. 2013;10(2):297-304. doi:10.1016/j.hrthm. 2012.10.020S1547-5271(12)01210-6[pii].

33. Calkins H, Kuck KH, Cappato R, Brugada J, Camm AJ, Chen SA, et al. 2012 HRS/EHRA/ECAS Expert Consensus Statement on Catheter and Surgical Ablation of Atrial Fibrillation: recommendations for patient selection, procedural techniques, patient management and follow-up, definitions, endpoints, and research trial design. Europace. 2012;14(4):528-606. doi:10. 1093/europace/eus027eus027[pii].

\section{Submit your next manuscript to BioMed Central} and we will help you at every step:

- We accept pre-submission inquiries

- Our selector tool helps you to find the most relevant journal

- We provide round the clock customer support

- Convenient online submission

- Thorough peer review

- Inclusion in PubMed and all major indexing services

- Maximum visibility for your research

Submit your manuscript at www.biomedcentral.com/submit 